\title{
Forest Fire Detection Techniques Survey based on Wireless Sensor Network
}

Abeer W Al-Sabbagh

\begin{abstract}
Every year, thousands of forest fires across the world occurs and cause disasters in the environment system including losses huge spaces of green area, thus, there is a realistic need for finding a solution to eliminate the impact of the forest fires. many applications and techniques/method used to identify forest fire in early stage. Each one of these techniques has advantage and disadvantage in term of the cost, energy and performance. This paper will Brows these methods and present a comparison between the forest fire detection techniques.
\end{abstract}

\section{Keywords}

Forest Fire Detection Techniques, Wireless Sensor Network, WSN

\section{INTRODUCTION}

Green areas have been decreasing rapidly in the last decades due to several reasons, urban expansion represented by Human behavior like; smoking, barbeque and using wood of tree as a fuel source, Natural causes like; high temperature (global warming). Unluckily, forest fire usually observed after its already spread over a large area, making it hard to control and even impossible at time and cause a big damage to nature, it has effect in atmosphere $(30 \%$ of carbon dioxide $(\mathrm{CO} 2)$ in the atmosphere comes from forest fires) [1].There are several techniques used for detecting and monitoring forest fire such as; Optical Sensors and Camera Surveillance, Satellite Based Systems, Wireless Sensor Networks (WSN). This paper will shed the light on these different techniques and systems used for the purpose of early detecting and forecasting the forest fire.

\section{SATELLITE BASED SYSTEMS}

The satellite based system is technology used to find out and detect the forest fire. Where there are two main satellites systems launched for forest fire detection purposes, the first is the advanced very high resolution radiometer (AVHRR) [2], which was launched in 1998, and second one is the moderate resolution imaging spectroradiometer (MODIS), that launched in 1999 [3]. The main problem with those systems is represented by the time needed to capture the area of the earth, where it is approximately 2 days then the images send to the Earth station to be processed and analyses. The time taken for this is calculated according to the following equation:

Time taken = Image Capturing time + Image Sending time + Processing and Analyzing time + Distribution time [4].

Furthermore, the quality of satellite images is affected by resolution of images, where small areas cannot be determined correctly when the process areas are zoomed to detect the forest fire due to the low resolution of images, as it shows in Figure 1 The figure display the characteristic of low resolution of image

\author{
Ahmad A. A. Alkhatib
}

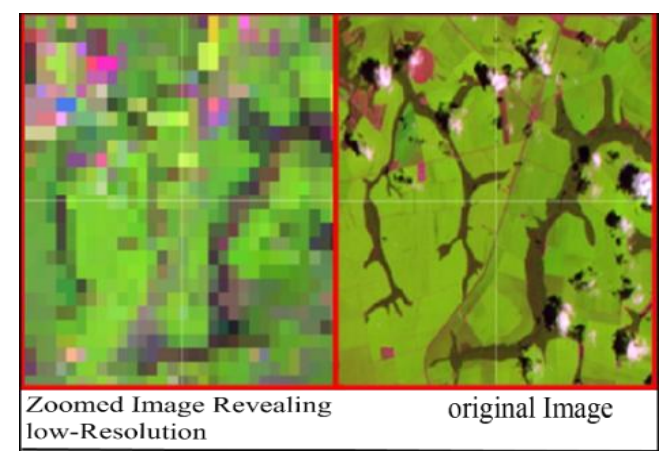

Fig 1. Characteristic of low resolution of image [4]

Also, the quality of images is influenced by the weather conditions, where clouds hide the images during the scanning period and accordingly affect the real time of processing the images and detecting the fire forest. Figure.2. Shows a realtime image of Forest Fires covered by clouds from top view [4].

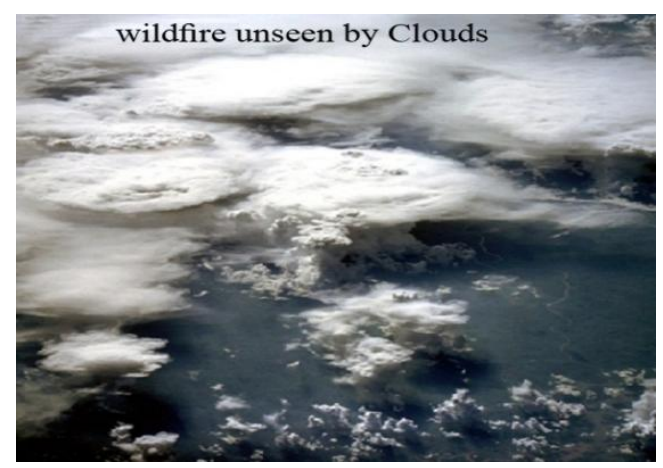

Fig. 2. A Real-time Image of Forest Fires Covered by Clouds from Top View[4]

However, any existing satellite-based observations for forest fires have different limitations that causing a failure in rapid and effective control for forest areas. These limitations are concentrated on the direct observation of forest fires from geostationary (GEO) or Low Earth Orbit (LEO) satellite. These satellites are located on orbits over 22,800 miles above the earth's surface, additionally, these satellite systems could not be provided with equipment's required for fire forest detection such as; transponders, antennas, amplifications and others.

\subsection{Optical Sensor and Digital Camera}

There are different alternative types of systems that have been used to detect the fire forest in early stages, such as; Optical Sensor and Digital Camera. Each of these systems has advantages and disadvantages that distinguish it from other systems and technologies. Whereas, the charge-coupled device (CCD) cameras and Infrared (IR) detectors are put on top of towers and sense the abnormal events and send it to the control center. Different circumstances affect these systems and reports sent by them such as; terrain, time, weather conditions, light reflection, and smoke from industries. Thus the optical sensors and cameras should be enhanced and developed in a way that 
reduce the false alarms resulting from different dynamic behaviors.

There is different types of detection sensors can be used in land systems such as; [5]

1. video-camera, sensitive to visible spectrum of smoke recognizable during the day and a fire recognizable at night.

2. Infrared (IR), thermal imaging cameras based on the detection of heat flow of the fire.

3. IR spectrometers to identify the spectral characteristics of smoke.

4. Light detection and ranging systems-LIDAR (detection of light and range) that measure laser rays reflected from the smoke particles.

\subsection{Wireless Sensor Network}

Wireless Sensor Network is developed as a new technology to detect forest fire in early stages, it received a worldwide attention specifically with the proliferation of Micro-ElectroMechanical system (MEMS) technology that has been used to develop the smart sensors. These sensors sense and collect the information from the environment and then transmit it to the user, the main features of these sensor is that it characterized as inexpensive and small with limited processing and computing resources, on the other hand these sensors have limited battery power and memory capacity, also it could be spread in areas that is difficult for humans to access. Wireless Sensor Networks have been used and applied in a large number of application such as Environmental monitoring, Acoustic detection, Seismic detection, Military surveillance, Process monitoring etc.[7] .

\section{RELATED WORK}

A.Alkhatib (2014), reviewed all techniques and methods used for forest fire detection, particularly, human based observation, satellite system, optical cameras, and wireless sensor networks. Also, illustrated a detailed discussion on those methods together with showing the advantages and disadvantages of each method, and gave examples on some researches results. Additionally, his work focused on some market product methods, and presented a comprehensive comparison between the four methods reviewed including the cost, efficiency and practically, faulty alarms repetition, fire localizing accuracy, detection delay, fire behavior information, and if they can be used for other purposes[6]. Furthermore Waqas et al. (2016), conducted also a survey on studies used various techniques implemented for the detection of forest fire, such as; optical sensors and camera surveillance, satellite based system, and wireless sensor networks. A discussion on the advantages and disadvantages of each method were presented on his paper as well [7].

As the wireless sensor networks (WSN) method proved its power features and effectiveness in detecting forest fire in early stages, a lot of researches focused on presenting the working mechanism of WSN. Patil et al. (2016), in his paper developed a forest fires surveillance system based on WSN for early detection of forest fires before it spreads to the entire forest. Different type of sensors used for this purpose like; smoke sensor, humidity sensor, and temperature sensor, where these sensors immediately recognize the amount of fire and send the required data to the forest officer, and accordingly help the nature from destroying and reduce the damage [14] .

Moreover, Mithan et al. (2016), highlighted in their paper the main characteristics and feature of the WSN as a prospective solution for the early detection of forest fire based on a device used different sensors attached and wireless data transmission, where the process of Transmission the data is performed as the following, the data collected will transmit to small satellite then the satellite transmitted the data received to the station to be processed and analyzed, Therefore the conclusion of their works stated that the WSN are the best available solution for early forest fire detection [15].

On the other hand and in order to monitor and evaluate the proposed WSN systems, Zhu et al.(2012), developed a monitoring system for forest fires, the system based on wireless sensor networks and GPRS network. in order to provide realtime monitoring for smoke, temperature, humidity, and some other environmental parameters, the system depend on clustering systems. The system designed in a way that the collected data from the nodes will be transmitted in multichip fashion to the central nodes and then to the monitoring center. Accordingly the system produce reports, graphs, and curves that used in taking proper decisions and actions [12].

Aslan (2010), draw a framework for the use WSNs in forest fire detection and monitoring. It included the design of four main components of a wireless sensor network namely: the deployment scheme, the logical topology and architecture of the network, the intra-cluster communication scheme, and the intercluster communication scheme. The communication between nodes and clusters spilled into four phases; (1) initialization phase, (2) risk free phase, (3) fire threat phase, and (4) progressed fire phase. The Nodes enter or change their phase depending on the danger rate calculation, which depends on NFDRS (National Fire Danger Rating System), temperature, and humidity ranges [11].

Solobera (2010), Another nodes called Waspmote were developed by Libelium which is one of the wireless sensor network companies based in Spain. The company presented many applications for their products such as smart cities, forest fire detection, and many other applications. For forest fire, the company used their Waspmote nodes and a GPS device to localize those nodes, and supplied the nodes with gas boards to measure temperature, humidity, carbonmonoxide ( $\mathrm{CO})$, and carbon dioxide $(\mathrm{CO} 2)$ to detect the fire [13].

Son et al (2006), developed forest fire detection system in the South Korean mountains through wireless sensor networks, Where WSNs connected to the internet and the information saved to be used for future risks. The system contains of WSNs, middleware and web application. They used a special protocol for routing which is MCF (minimum cost path forwarding), the MCF required a routing table for each sensor node to find a minimum path to the base station. The system work as the following the sensors collecting the information and sending it to the base station node after that sending it to the gateway which connected to middle ware and web application, then it make a daily analysis for the data collected and looks for the possibility of an event [10].

As well as, wireless sensor network for wildfire monitoring was proposed by Doolin and Sitar (2005), in which they used different environmental sensors to sense the temperature, humidity, and barometric pressure. Also, they connected a GPS device with each node to collect data and transmit it to the basic station. The main problems with this system concentrated with the cost and power, where using a GPS device with every sensor node will increase the cost of the network and make it very expensive, and it will consume more power and decrease the network lifetime [8] 
Yu et al. (2005), also focused on real-time forest fire detection with wireless sensor network. They have used neural wireless sensor network to lengthen the network life time, used the clustering algorithm for routing the data in which the nodes sends the sensed data to the cluster head and then to the base station. As well as, the in-network processing approach has been used to save energy consumption through decrease communication between nodes [9].

\section{DISCUSSION}

There is many techniques used to detect forest fire in early stages, this paper focused on three techniques namely; the satellite based system, optical sensor and digital camera, and wireless sensor network, and it proposed the pros and cons for each one with the focus on WSN as a best technique used to detect forest fire. The table below illustrate a comparison between these techniques as state in Alkhatib [6].

\section{CONCLUSION}

After conducting a comparison between the different methods used for detecting the forest fire, the WSN proved that it had been considered as the optimal system that could be used and modify for the purpose of forest fire detection for many reasons such as; easy to deploy, inexpensive device, used in deferent application, transferring information with minimum delay comparing with other two techniques, using different sensors to collect different data. In the future, we will focus on using wireless network sensors for the application of forest fire detection by making some improvement on sensing range coverage accuracy through increasing sensing range and decreasing the cost by declining the total number of deployed sensors.

Table 1. Comparison between forest fire detection systems [6].

\begin{tabular}{|l|l|l|}
\hline $\begin{array}{l}\text { Human based } \\
\text { observation }\end{array}$ & Satellite system & Optical cameras \\
\hline $\begin{array}{l}\text { Last decade, mainly } \\
\text { budget cuts and } \\
\text { reorganization on of } \\
\text { departments have been } \\
\text { focused on } \\
\text { "suppression" which in } \\
\text { turn allows fuel levels } \\
\text { to continue to increase, }\end{array}$ & $\begin{array}{l}\text { Any existing satellite-based } \\
\text { observations for forest fire suffer from } \\
\text { severe limitations resulting in a failure in } \\
\text { speedy and effective control for forest } \\
\text { areas. }\end{array}$ & $\begin{array}{l}\text { Optical sensors or camera } \\
\text { systems in general need to be } \\
\text { improved in order to reduce the } \\
\text { number of false alarms due to } \\
\text { various dynamic phenomena, such } \\
\text { as wind-tossed trees, cloud } \\
\text { shadows, reflections, and human } \\
\text { activity. }\end{array}$
\end{tabular}
thus providing the basis for catastrophic fires to occur.

\section{Authorities'}

techniques are based on the probability of human observation or the forecast predictions for forest fires, but it is not the reliable solution that can stop this problem or reduce it.

They do not consider the environmental impact as a priority.

High probability of faulty alarms. coverage may be only intermittent (not continuous in time), with substantial gaps in time when the satellite is not within the field of view from certain regions or spots of the forest.

The optical and the infrared (heat) spectral radiation emitted by a small flame, the early phase of a forest prior to its spread over a wide region, may be too feeble in intensity to be detected by a satellite. The intensity decreases as the inverse square of the distance, in addition to being sensitive to the angle between the direction of the arriving beam of radiation and the normal to the receiving surfacemirror, camera, antenna, and detector so that position and orientation of the satellite may usually be far from optimal for detecting a forest fire at an early phase.

The satellite may not be equipped with transponders and antennas designed to perform the reception, amplification, regeneration, frequency translation, and downlink transmission to the groundoptimally suited for detection of forest fires. In fact there may not yet be formal allocation of the appropriate frequency and bandwidth for forest fire detection and pertinent information transmission and processing (onboard or at the ground terminal or earth station).

A satellite is usually designed to perform many diverse functions (telecommunications, remote-sensing for broad features of the earth's surface or the atmosphere, etc.) and it is not cost-
The difficulties of processing landscape images are due to their varying nature and to the large number of dynamic events that may appear under various illumination conditions, depending on weather, distance, time of day, masking objects, and so forth.

These events produce dynamic envelopes, which are not always caused by motion, and consist of time-varying gray levels of connected pixels in several image regions.

This kind of technology only provides a line of sight vision; where high trees or the hills and mountains can block the vision; plus it might be impossible to provide images for ignition place.

Optical systems were designed to cover large areas with minimum numbers of camera towers; each tower has to detect smoke in range of $15-80 \mathrm{Km}$, where it requires a long delay after the ignition to produce a watchable smoke cloud that can be detected by the camera.

Weather condition and night vision reflect on the camera performance.

Camera surveillance systems with short distance links were tried, but this also proved an ineffective

$\begin{aligned} & \text { Wireless sensor } \\ & \text { networks }\end{aligned}$
$\begin{aligned} & \text { Best available } \\ & \text { solution for forest fire } \\ & \text { detection. }\end{aligned}$

They can provide all required information that influences the environment at any moment accurately. They can cover any area size, plus its scalable network.

They can observe and influence the physical world around them They can be connected to many devices and can add many kinds of sensors to measure different parameters.

There is no need to build towers or set up complicated

communication links.

They can be deployed anywhere even in inaccessible places. 


\begin{tabular}{|l|l|l|l|}
\hline $\begin{array}{l}\text { effective to add to it the capability to } \\
\text { detect forest fire. }\end{array}$ & $\begin{array}{l}\text { method for fire detection in regard } \\
\text { to the need for manual installment } \\
\text { for each camera in an appropriate } \\
\text { position rather than the line of sight } \\
\text { not be real time in order to } \\
\text { instantaneously provide information about } \\
\text { the occurrence of a forest fire anywhere } \\
\text { within the forest region. }\end{array}$ & $\begin{array}{l}\text { images problems, and high } \\
\text { possibility of false alarms because } \\
\text { of the daily motion of sun light, } \\
\text { clouds, atmospheric extinction, and } \\
\text { vegetation. } \\
\text { The operation of a satellite system is } \\
\text { regulations and agreements and may be } \\
\text { less than suitable for the task of forest fire } \\
\text { observation. }\end{array}$ & $\begin{array}{c}\text { Finally, these systems are very } \\
\text { expensive; the camera tower can be } \\
\text { worth more than thirty thousand } \\
\text { dollars per tower, and there is a } \\
\text { need to build these towers and } \\
\text { install a communication } \\
\text { infrastructure in the remote areas } \\
\text { inside the forests. }\end{array}$ \\
\hline
\end{tabular}

\section{ACKNOWLEDGMENT}

I would like to express my special thanks of gratitude to DR .Ahmad Alkhatib who gave me the golden opportunity to complete this paper and hold it to the punishment stage .I am really thankful to him. Also I would like to thank all my friends for their endless support.

\section{REFERENCES}

[1] An Inconvenient Truth, "Directed by Davis Guggenheim about former United States Vice President Al Gore's campaign [Documentary]," Los Angeles, NY, USA.

[2] NOAA satellite and information service, "Advanced Very High Resolution Radiometer-AVHRR,” 2012, http://noaasis.noaa.gov/NOAASIS/ml/avhrr.html.

[3] NASA, "MOIDS, National Aeronautics and space administration," 1999, http://modis.gsfc.nasa.gov/.

[4] U. Arun Ganesh, M. Anand, S. Arun, M. Dinesh, P. Gunaseelan and R. Karthik " Forest Fire Detection Using Optimized Solar - Powered Zigbee Wireless Sensor Networks" International Journal of Scientific \& Engineering Research, Volume 4, Issue 6, June-2013 ISSN 2229-5518

[5] EUFOFINET Project Detection Synthesis of Good Practices, National Forest Centre, Zvolen, Slovakia.

[6] Ahmad A. A. Alkhatib" A Review on Forest Fire Detection Techniques" International Journal of Distributed Sensor Networks Volume 2014, Article ID597368, http://dx.doi.org/10.1155/2014/597368

[7] Waqas Ali, Abdullah, Ishfaq-ur-rashid“A Survey on WSNbased Forest Fire Detection Techniques "International Journal of Scientific Research in Computer Science, Engineering and Information Technology (C) 2016 IJSRCSEIT | Volume 1 | Issue 1 | ISSN : 2456-3307
[8] D.Doolin andN. Sitar, Wireless Sensors for Wild FireMonitoring, Smart Structure and Material, San Diego, Calif, USA, 2005.

[9] L. Yu, N. Wang, and X. Meng, "Real-time forest fire detection with wireless sensor networks," in Proceedings of the International Conference onWireless Communications, Networking and Mobile Computing (WCNM'05), pp. 1214-1217, September 2005.

[10] Son, Y. Her, and K. Kim, "A Design and Implementation of Forest-Fires Surveillance System based on Wireless Sensor Networks for South Korea Mountains," International Journal of Computer Science and Network Security, vol. 6, no. 9, pp. 124-130, 2006.

[11] Y. Aslan, A framework for the use of wireless sensor networks in the forest fire detection and monitoring [M.S. thesis], Department of Computer Engineering, The Institute of Engineering and Science Bilkent University, 2010.

[12] Y. Zhu, L. Xie, and T. Yuan, "Monitoring system for forest fire based on wireless sensor network," in Proceedings of the $10^{\text {th }}$ World Congress on Intelligent Control and Automation (WCICA'10), 2012

[13] J. Solobera, "Detecting Forest Fires using Wireless Sensor Networks withWaspmote," Libelium, 2010.

[14] Mr. Lalit Patil, Miss. Divya Chopda, Miss. Prachi Jadhav, Miss Mansi Borse “ Forest-Fire Surveillance System Based on Wireless Sensor Network, International Journal of Engineering Research and applications. ISSN:22489622. Vol. 6, Issue 4, (part-2) April 2016, pp.14-15.

[15] Mithun B N, Asst. Prof, Shambhavi S V, Sneha J P, ChANDAN m, "Detection of Forest Fire Detection using Wireless Sensor Networks " $8^{\text {th }}$ Sem ISE, APSCE, Bengaluru-82. International Journal of Advancement in Engineering Technology, Management \& Applied Science. ISSN NO: 2349-3224. Volume 3, Issue 2 May 2016. 